\title{
Primary Cutaneous Follicle Center Lymphoma of the Eyelid: A Case Report and Review of the Literature in Light of Recent Changes to the WHO Classification of Lymphoid Neoplasms
}

\author{
Astrid C. Werner ${ }^{a}$ Nora V. Laver ${ }^{a}$ Dan S. Landmann ${ }^{b}$ \\ ${ }^{a}$ Tufts Medical Center - New England Eye Center, Boston, MA, USA; ${ }^{b}$ Hackensack University Medical Center, \\ Hackensack, NJ, USA
}

\section{Established Facts}

- Primary cutaneous follicle center lymphoma (PCFCL) is a rare diagnosis whose classification has recently changed.

- The histopathology of PCFCL can change significantly with the age and stage of the lesion.

\section{Novel Insights}

- Re-biopsy is an important consideration when clinical course is not consistent with the pathologic diagnosis.

\section{Keywords}

Primary cutaneous follicle center lymphoma - Lymphoma · Histopathology · Immunophenotype · Eyelid

\footnotetext{
Abstract

Primary cutaneous follicle center lymphoma (PCFCL) is a unique entity that represents up to $11 \%$ of all cutaneous lymphomas. PCFCL is associated with an indolent course and excellent 5 -year survival rates, but can progress to secondary systemic involvement if left untreated. Histopathologic features of PCFCL can vary depending on the size, duration, and
}

clinical stage of the lesion, making diagnosis somewhat challenging. Here, we present a case of a 50-year-old woman with an eyelid lesion that was initially classified as an inflamed cyst based on biopsy, but 1 year later, was determined to be PCFCL after repeat biopsy revealed different histology. In light of the recent changes to the WHO classification of lymphoid neoplasms, we review the unique clinical and histopathologic features of PCFCL that distinguish it from other more aggressive forms of cutaneous lymphoma in terms of course, prognosis, and management.

(c) 2018 S. Karger AG, Basel

\section{KARGER}

(C) 2018 S. Karger AG, Basel

E-Mail karger@karger.com

www.karger.com/oop
Astrid Werner, MD

Tufts New England Eye Center

260 Tremont St.

Boston, MA 02111 (USA)

E-Mail acwerner@gmail.com 


\section{Introduction}

Primary cutaneous follicle center lymphoma (PCFCL) is the most common B-cell lymphoma of the skin and is composed of malignant $\mathrm{B}$ cells originating in follicle germinal centers. By definition, PCFCL presents in the skin only without evidence of extracutaneous disease at the time of diagnosis and after completion of an initial staging evaluation. It has a unique immunophenotype and clinical course when compared to nodal follicular lymphoma. There are three different growth patterns: follicular, diffuse, or follicular and diffuse growth pattern [1]. Typically, PCFCL presents as a solitary lesion or series of grouped erythematous lesions on the head or trunk that gradually increase in size over time if untreated. The clinical course of all subtypes of PCFCL is usually indolent with rare extra-cutaneous extension and excellent 5-year survival rates (95\%) when treated with local radiation alone. This is in contrast to the more aggressive primary cutaneous diffuse large B-cell lymphomas, which have 5 -year survival rates ranging from 50 to $65 \%$ and require chemotherapy in addition to local radiation [2]. Herein, we present a case of a 50-year-old woman with a PCFCL of the eyelid that was initially misdiagnosed as an inflamed ruptured cyst.

\section{Case Report}

A 50-year-old woman presented to the ophthalmology clinic with a lesion on the right lower eyelid, near the medial canthus, that had been enlarging over the past year. The lesion was nonmobile, measured $4 \times 3 \mathrm{~mm}$, and had an erythematous, firm, "stuck-on" appearance. The lesion had overlying telangiectasias, but was non-tender and non-ulcerated (Fig. 1a). Of note, 1 year previously, the patient had undergone an incisional biopsy of the same lesion at a different institution, and the pathology specimen was determined to be an inflamed, ruptured cyst (Fig. 2). The lesion continued to enlarge, and a second biopsy was performed 1 year later as the clinical appearance was concerning for basal cell carcinoma.

The patient was otherwise healthy with no significant medical or ocular history, and her ocular and systemic review of systems was otherwise negative. She had no personal or family history of cutaneous malignancies. She had no history of immunosuppression.

The pathology specimen revealed an atypical, nodular lymphoid infiltrate within the dermis, sparing the epidermal layer (Fig. 3a). The atypical lymphocytes were small in size with moderate amounts of pale cytoplasm, irregular nuclear contours, clumped chromatin, and indistinct nucleoli (Fig. 3b). Scattered large lymphocytes reminiscent of centroblasts were identified numbering fewer than 10 cells per HPF. No sheets or aggregates of large lymphocytes were identified. Immunohistochemical
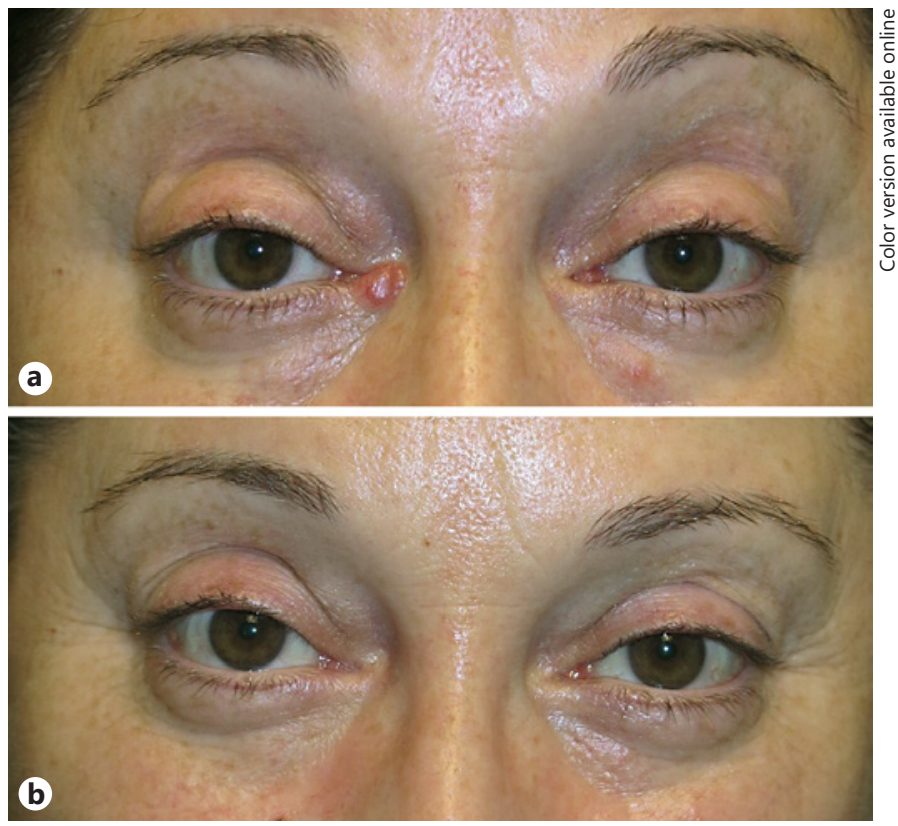

Fig. 1. a Initial lesion was a $4 \times 3 \mathrm{~mm}$ immobile, erythematous, "stuck-on" appearing mass with overlying telangiectasias. b Lesion at 6 months follow-up after local radiation and concomitant rituximab.

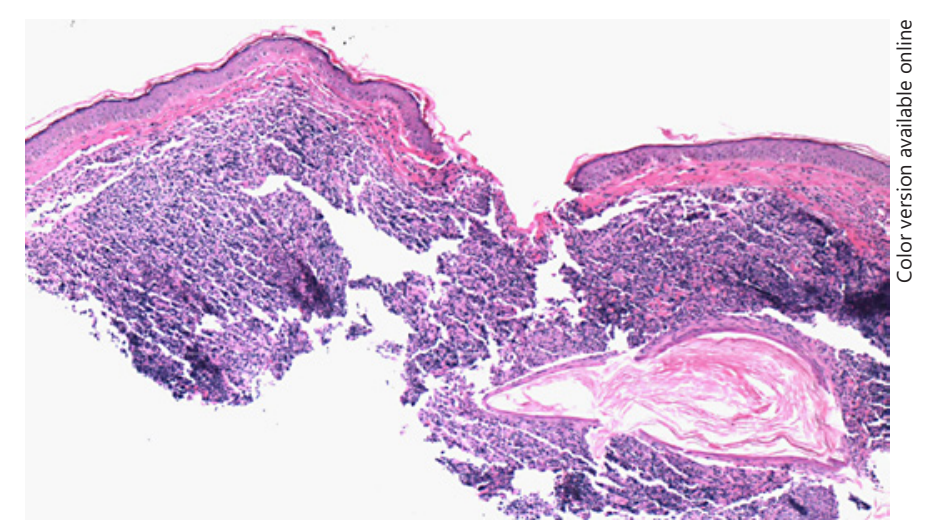

Fig. 2. Initial specimen 1 year prior to presentation reveals a cystic structure with infiltrating lymphocytes suggestive of an inflamed cyst.

staining showed that these atypical lymphocytes were B cells of the following phenotypes: CD20+, CD 10- (Fig. 3c), BCL6+, BCL2+ (Fig. 3d), CD5-, CD23+, cyclin D1-, CD43-. Staining for CD30+ highlighted rare cells, around $1-2 \%$ of the population. The proliferation index as assessed by Ki-67 immunohistochemical stain was approximately $5 \%$ overall. Genetic studies were negative for $\mathrm{t}(14 ; 18)$. Flow cytometry was not performed. The overall findings were considered diagnostic for a low-grade B-cell non-Hodgkin lymphoma of follicle center cell origin. 

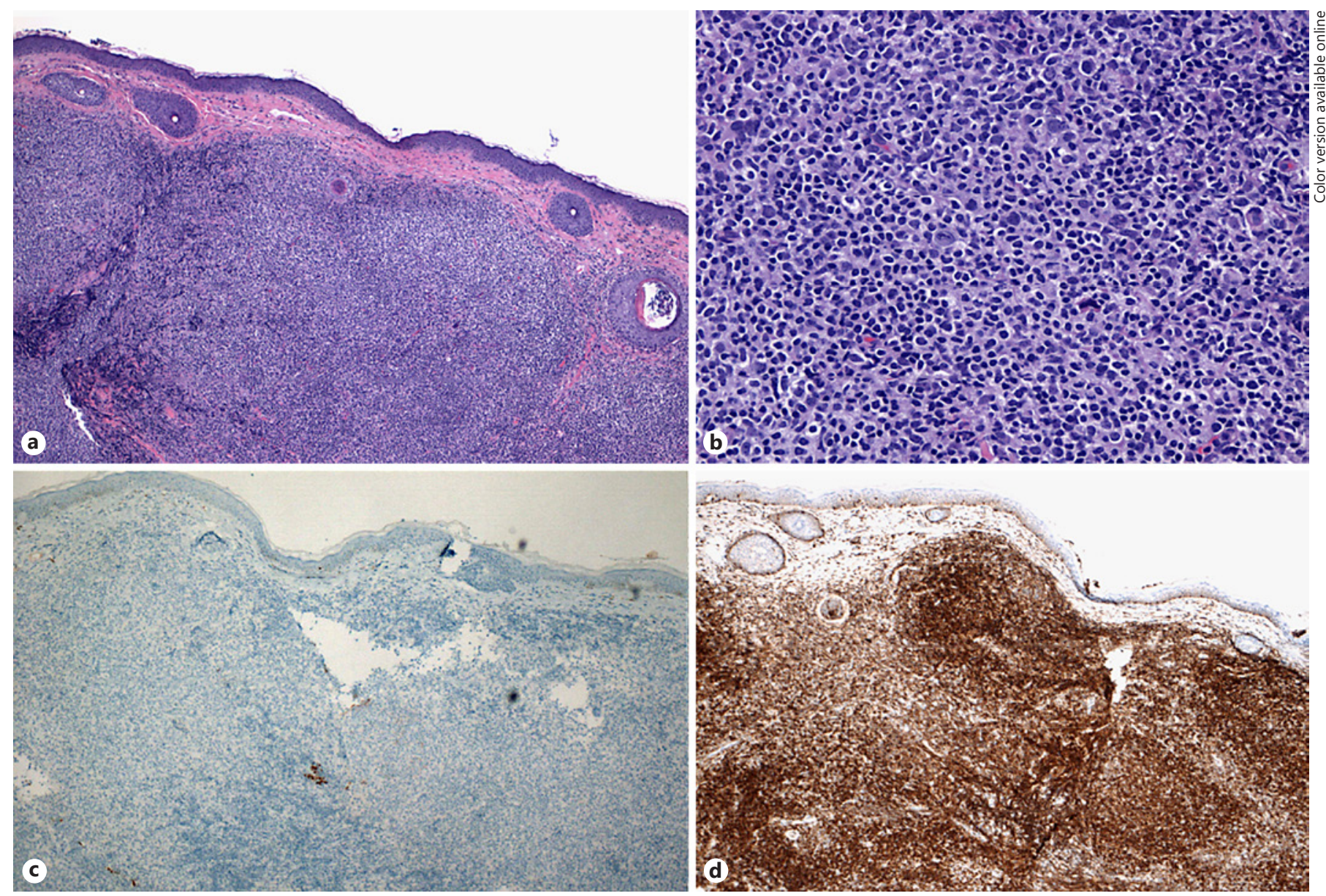

Fig. 3. a $10 \times$ magnification of lesion reveals an atypical, nodular lymphoid infiltrate within the dermis that spares the epidermis. b $40 \times$ magnification shows small, atypical lymphocytes with moderate amounts of pale cytoplasm, irregular nuclear contours, clumped

The patient subsequently underwent a complete systemic workup including lab work, bone marrow biopsy, and positron emission tomography (PET) scan. Complete blood count, complete metabolic panel, erythrocyte sedimentation rate, lactate dehydrogenase, and serum protein electrophoresis were all within normal limits. Peripheral blood did not show evidence of a B- or $\mathrm{T}$-cell lymphoproliferative disorder. Bone marrow biopsy revealed normocellular marrow for age with trilineage hematopoiesis, without evidence of follicular lymphoma. PET scan showed no evidence of increased metabolic activity. Infectious workup including hepatitis C, Borrelia burgdoferi, and HIV serologies, each of which has been associated with PCFCL, were negative.

The patient was diagnosed with a PCFCL and chose to defer further excision in favor of local radiation and concomitant rituximab. A Mini Monoka stent was placed prophylactically on the treated side, as the lesion was overlying the canaliculus. At the 6-month follow-up, there was no recurrence of the cutaneous lesion and no evidence of systemic involvement (Fig. 1b).

PCFCL of the Eyelid: A Case Report and Review of the Literature chromatin, and indistinct nucleoli. Note the scattered large lymphocytes reminiscent of centroblasts, and lack of lymphocyte sheets or aggregates. c The specimen exhibits minimal CD10 staining. d There is diffuse BCL 2+ staining, more dense in the follicular centers.

\section{Discussion}

Proper classification of cutaneous lymphomas is a critical issue because of its implications for prognosis and treatment. B-cell lymphomas represent up to $25 \%$ of cutaneous lymphomas, while the majority are of T-cell derivation. Among cutaneous B-cell lymphomas, there has been significant debate in recent years regarding two entities: PCFCL and primary cutaneous large B-cell lymphoma of the leg (PCLBCL-leg). PCLBCL-leg has long been recognized as an entity that carries a more unfavorable prognosis, but there has been discussion as to whether it is a unique entity or rather a subtype of PCFCL [3-6]. In 2016, the World Health Organization (WHO) revised its classification system of cutaneous B-cell lymphomas with three main subtypes [7]:

Ocul Oncol Pathol 2019;5:147-152 
- PCFCL

- Primary cutaneous diffuse large B-cell lymphoma, leg type

- Primary cutaneous marginal zone lymphoma

Based on these new criteria, PCFCL is recognized as a unique entity that represents up to $11 \%$ of all cutaneous lymphomas and $40-50 \%$ of cutaneous B-cell lymphomas [2]. Whereas PCFCLs of all growth patterns follow an indolent course and have excellent 5-year survival rates with excision and radiotherapy alone (95\%), more aggressive primary cutaneous diffuse large B-cell lymphomas have 5-year survival rates ranging from 50 to $65 \%$ and require chemotherapy in addition to local radiation [2].

Classically, PCFCL presents as single or multiple erythematous plaques or nodules grouped at a single site on the head, neck, trunk, and much less commonly on the lower extremities $[2,8]$. The lesions are typically non-ulcerated. In practice, however, PCFCL can take many forms. There have been cases of PCFCL documented in the literature presenting with ill-defined, hypochromic, flat lesions, erythematous macules expanding in a centrifugal pattern on the back known as "reticulohistiocytoma of the dorsum," acneiform lesions of the face, and a miliary pattern involving the head and neck [1, 9-13].

The histopathology of PCFCL varies depending on the size, duration, and clinical stage of the lesion [8]. Typically, most lesions show a nodular (in follicular growth pattern) to diffuse infiltrate that involves the entire dermis and can extend into the subcutaneous adipose tissue but spares the epidermis [2,8]. A follicular pattern is more often observed in scalp lesions than in lesions of the trunk $[2,14]$. The cells involved include centrocytes, centroblasts, reactive $\mathrm{T}$ cells, and large neoplastic $\mathrm{B}$ cells. Large, multi-lobulated centrocytes are particularly characteristic of PCFCL $[2,8]$. As lesions progress, the neoplastic B cells increase in number and size, while the proportion of reactive $\mathrm{T}$ cells decreases, and recognizable follicular structures disappear [2]. Recognizing these histopathological features in a biopsy might be challenging if the biopsy is too shallow, if it is from the edge of the lesion, or if the changes are early with mostly reactive $\mathrm{T}$ lymphocytes and macrophages.

The histopathological differential diagnosis of PCFCL includes follicular lymphoma, primary nodal type, extranodal marginal zone lymphoma (especially one with neoplastic colonization of reactive germinal centers) and an unusual presentation of mantle cell lymphoma with soft tissue involvement, and diffuse large B-cell lymphoma. Based on $\mathrm{H} \& \mathrm{E}$ and immunohistochemical findings alone, a diagnosis of benign reactive follicular hyperplasia also enters the differential diagnosis.

Immunophenotypically, the neoplastic B cells in PCFCL co-express CD20, CD19, CD22, and CD79a cell markers, and consistently express bcl-6. Follicular and diffuse pattern PCFCLs differ based on CD10 expression: diffuse pattern PCFCL tends to be CD10-, while follicular is more often $\mathrm{CD} 10+$. Both diffuse and follicular PCFCLs occur against a background of CD21+ dendritic cells, which helps to confirm the germinal center origin of the tumor $[2,15]$. PCFCL tends to show reduced Ki-67 (MIB1) staining (50\%) indicating decreased proliferation compared to normal germinal centers, which have a very high degree of proliferating cells (>90\%) [10]. The patient presented in this case was found to be $t(14 ; 18)$ negative but diffusely bcl-2 positive. The lack of $t(14 ; 18)$ is typical of PCFCL and is an important feature that differentiates it from secondary nodal follicular lymphoma with cutaneous involvement. Bcl-2 positivity, however, is more typical of nodal follicular lymphoma and occurs in only 10$15 \%$ of PCFCL cases [15]. Just as in nodal follicular lymphoma, overexpression of this antiapoptotic protein appears to portend a more unfavorable prognosis, reducing 5 -year survival from $89 \%$ to $42 \%$ in one study [16]. Of note, PCLBCL-leg type tends to express bcl-2 more often, perhaps accounting for its worse prognosis.

Clinicopathologic features alone cannot differentiate between PCFCL and secondary involvement of extra-cutaneous lymphoma. Complete systemic workup in collaboration with a multidisciplinary team of specialists in hematology, dermatology, and pathology is required for diagnosis. In addition to biopsy, initial workup should include complete physical examination, laboratory testing, chest X-ray, computed tomography of the chest, abdomen and pelvis, and a bone marrow biopsy. Laboratory testing should include complete blood count, urinalysis, liver function tests, lactate dehydrongenase, C-reactive protein, protein electrophoresis, immunoglobulins, and serologic testing for hepatitis, Borrelia burgdorferi, and HIV [8]. A lesion can only truly be defined as PCFCL when skin disease is present alone for at least 6 months after complete staging [6].

Radiotherapy is considered the first-line therapy for PCFCL. If lesions are localized, excision of the tumor followed by radiation to the area should be undertaken. Recently, ultralow dose radiation with $4 \mathrm{~Gy}$ to the orbit in two 2-Gy doses has been shown to be curative in a majority of patients, while maintaining local control in those who ultimately require the current standard dose of $24 \mathrm{~Gy}$ [17]. Relapses occur in $25-29 \%$ of patients after standard treatment, 
and, as long as there is no further evidence of systemic involvement or spread at the time of recurrence, further radiation can be utilized [18]. Systemic treatment with chemotherapy is reserved for patients with extensive or diffuse disease or extracutaneous spread. Recently, rituximab has been added to systemic therapy with some success, as has systemic and intralesional interferon alpha $[15,19,20]$.

The case presented highlights the importance of rebiopsying lesions that do not follow the typical expected course of the prior histopathological diagnosis - in this case a diagnosis of an inflamed ruptured cyst. Questioning the initial diagnosis averted possible significant local destruction or secondary systemic spread from untreated cutaneous lymphoma - an especially negative outcome given the lesion's excellent prognosis with appropriate management. As described above, the histopathology of the PCFCL can change significantly with the age and stage of the lesion and may appear reactive in early stages. The early stage of the lesion, low number of cells, and the confounding presence of a cyst in initial biopsy contributed to the original missed diagnosis and subsequent clearer histopathological picture. This case nicely illustrates the typical histology and immunophenotype of PCFCL, although the patient's BCL2+ status does represent a minority of PCFCL cases. Given her BCL2+ positivity and its associated poorer prognosis, this patient warrants close follow-up for evidence of recurrence or systemic spread.

\section{Conclusion}

All patients with a cutaneous lesion that does not follow the expected course of the prior histopathological diagnosis warrant reconsideration with a second biopsy. PCFCL is among the more unusual diagnoses seen in an ophthalmology clinic, and while classically these lesions have an erythematous nodular appearance, they can actually take on many forms. Appropriate diagnosis requires tissue biopsy and a complete systemic workup to rule out secondary cutaneous extension of a systemic lymphoma. The diagnosis of PCFCL typically carries an excellent prognosis after local treatment with local radiation.

\section{Statement of Ethics}

This study is a case report and did not require approval by our institutional Ethics Committee; however, individual patient consent was obtained to publish medical history and clinical photographs.

\section{Disclosure Statement}

All authors declare that there are no conflicts of interest to disclose.

\section{References}

1 Gulia A, Saggini A, Wiesner T, Fink-Puches R, Argenyi Z, Ferrara G et al. Clinicopathologic features of early lesions of primary cutaneous follicle center lymphoma, diffuse type: implications for early diagnosis and treatment. J Am Acad Dermatol. 2011 Nov;65(5): 991-1000.

2 Willemze R, Jaffe ES, Burg G, Cerroni L, Berti E, Swerdlow SH et al. WHO-EORTC classification for cutaneous lymphomas. Blood. 2005 May; 105(10):3768-85.

3 Willemze R, Meijer CJ, Scheffer E, Kluin PM, Van Vloten WA, Toonstra J et al. Diffuse large cell lymphomas of follicular center cell origin presenting in the skin. A clinicopathologic and immunologic study of 16 patients. Am J Pathol. 1987 Feb;126(2):325-33.

4 Willemze R, Meijer CJ, Sentis HJ, Scheffer E, van Vloten WA, Toonstra J et al. Primary cutaneous large cell lymphomas of follicular center cell origin. A clinical follow-up study of nineteen patients. J Am Acad Dermatol. 1987 Mar;16(3 Pt 1):518-26.

PCFCL of the Eyelid: A Case Report and Review of the Literature
5 Willemze R, Kerl H, Sterry W, Berti E, Cerroni L, Chimenti S, Diaz-Peréz J, Geerts M, Goos M, Knobler R, Ralfkiaer E, Santucci M, Smith N, Wechsler J, van Vloten WA, Meijer CJ. EORTC classification for primary cutaneous lymphomas: a proposal from the Cutaneous Lymphoma Study Group of the European Organization for Research and Treatment of Cancer. Blood. 1997 Jul;90(1):354-71.

6 Hossfeld DK. Jaffe E, Harris N, Stein H, J.W. Vardiman (eds). World Health Organization Classification of Tumours: Pathology and Genetics of Tumours of Haematopoietic and Lymphoid Tissues. Ann Oncol. 2002 Mar; 13(3):490-1.

7 Swerdlow SH, Campo E, Pileri SA, Harris NL, Stein H, Siebert R et al. The 2016 revision of the World Health Organization classification of lymphoid neoplasms. Blood. 2016 May; 127(20):2375-90.

8 Ceovic R, Jovanovic I, Kostovic K, Rados J, Dotlic S, Radman I et al. Radiotherapy of primary cutaneous follicle center lymphoma: case report and review of literature. Radiat Oncol. 2013 Jun;8(1):147.
9 Massone C, Fink-Puches R, Cerroni L. Atypical clinical presentation of primary and secondary cutaneous follicle center lymphoma (FCL) on the head characterized by macular lesions. J Am Acad Dermatol. 2016 Nov: 75(5):1000-6.

10 Cerroni L, Kerl H. Primary cutaneous follicle center cell lymphoma. Leuk Lymphoma. 2001 Sep-Oct;42(5):891-900.

11 Soon CW, Pincus LB, Ai WZ, McCalmont TH. Acneiform presentation of primary cutaneous follicle center lymphoma. J Am Acad Dermatol. 2011 Oct;65(4):887-9.

12 Massone C, Fink-Puches R, Laimer M, Rütten A, Vale E, Cerroni L. Miliary and agminatedtype primary cutaneous follicle center lymphoma: report of 18 cases. J Am Acad Dermatol. 2011 Oct;65(4):749-55.

13 Chockalingam R, Aneja S, Patel AB. Primary cutaneous follicle center lymphoma mimicking folliculitis. Cutis. 2018 Jan;101(1):E30E33. 
14 Cerroni L, Arzberger E, Pütz B, Höfler G, Metze D, Sander CA et al. Primary cutaneous follicle center cell lymphoma with follicular growth pattern. Blood. 2000 Jun;95(12): 3922-8.

15 Hoefnagel JJ, Vermeer MH, Jansen PM, Fleuren GJ, Meijer CJ, Willemze R. Bcl-2, Bcl-6 and CD10 expression in cutaneous B-cell lymphoma: further support for a follicle centre cell origin and differential diagnostic significance. Br J Dermatol. 2003 Dec;149(6): 1183-91.

16 Grange F, Petrella T, Beylot-Barry M, Joly P, D'Incan M, Delaunay M et al. Bcl-2 expression is strongest independent prognostic factor of survival in cutaneous B cell lymphomas. Blood. 2004 May;103(10):3662-8.
16 Pinnix CC, Dabaja BS, Milgrom SA, Smith GL, Abou Z, Nastoupil L et al. Ultra-low-dose radiotherapy for definitive management of ocular adnexal B-cell lymphoma. Head Neck. 2017 Jun;39(6):1095-100.

17 Senff NJ, Hoefnagel JJ, Neelis KJ, Vermeer MH, Noordijk EM, Willemze R; Dutch Cutaneous Lymphoma Group. Results of radiotherapy in 153 primary cutaneous B-Cell lymphomas classified according to the WHOEORTC classification. Arch Dermatol. 2007 Dec;143(12):1520-6.
18 Fabbri A, Cencini E, Alterini R, Rubegni P, Rigacci L, Delfino C et al.; Gruppo Italiano Linfomi Cutanei (GILC). Rituximab plus liposomal pegylated doxorubicin in the treatment of primary cutaneous B-cell lymphomas. Eur J Haematol. 2014 Aug;93(2):129-36.

19 Vandersee S, Terhorst D, Humme D, Beyer $\mathrm{M}$. Treatment of indolent primary cutaneous B-cell lymphomas with subcutaneous interferon-alfa. J Am Acad Dermatol. 2014 Apr; 70(4):709-15.

20 Rubegni P, De Aloe G, Pianigiani E, Lazzi S, Fimiani M. Primary cutaneous B-cell lymphoma: treatment with low dose intralesional recombinant interferon-alpha 2A. J Eur Acad Dermatol Venereol. 1999 Jan;12(1):70-1. 